\title{
A systems approach to mining innovation
}

\author{
DM Morrison Centre for Excellence in Mining Innovation, Canada \\ V Drylie Centre for Excellence in Mining Innovation, Canada \\ PO Labrecque Labrecque Technologies Inc., Canada
}

\begin{abstract}
Any innovation in part of the mining process has to be integrated into a production system. The mineral dressing system and the tailings management system are easily recognisable as process systems, managed by trained process engineers. The mining process, and especially the underground mining process, have somehow escaped the constraints imposed by the process engineering included in manufacturing operations and is still regarded as a series of almost separate activities - drill-and-blast, ventilation, ground support, ore transfer, and backfilling, each with its own specific expertise and practitioners. This discrete approach has been successful for relatively small-tonnage operations, but it begins to fail as the daily production demand increases.

Many underground metal mines using bulk mining and fill have been successful in producing 5,000-8,000 tpd, and the same production equipment platform was adopted for block caving operations in low-grade copper porphyry operations to achieve more than 50,000 tpd. These mines are struggling to meet design targets of $100,000 \mathrm{tpd}$, at the same time that bulk mining operations are struggling to maintain their production levels with greater ventilation and logistical challenges at depth. The inability to meet current production targets has led to a series of tactical responses, such as layout changes, equipment automation and electrification, and other new technologies. We make the case that the implementation of isolated technologies into deep, high-tonnage operations are unlikely to be successful unless they are integrated into a mine production system that is designed to address all the system constraints. We believe that the last technological transition has created a progress trap that will prevent mines achieving higher production rates. We believe a 'systems approach' to mining innovation is essential if we are to transition to technology platforms that can meet future performance targets, match demographic projections and enable the industry to meet future metal demand.
\end{abstract}

Keywords: Theory of Constraints, high-tonnage operations, technology transformation, progress trap

\section{Introduction}

There has been a gradual decline in the economic performance of the metal mining industry over the last decade (Deloitte 2017). This has to be reversed, and this can only be achieved by transforming the way mines operate. In underground mines there is already a transition to greater use of autonomous and continuous production systems to improve underground mine performance, and this will also require a significant change in the machine intelligence of this equipment. But we believe what is required is a radical improvement of the economic performance of the industry, driven by a wholescale transformation of the technological and social profile of the industry.

It has become common for mining to look to other sectors of the economy to see how they are managing through transition in the digital age. However, the mining industry is at the heavy end of the heavy-industry spectrum and the rate of change in software apps on cell phones is not helpful. The rate of change in any industry is related to the cost of innovation failure and the adoption rate of the core customer. Errors in coding for software apps can be corrected quickly and cheaply; not so heavy equipment prototypes. Unlike public consumers of cell phones and other high-tech gadgets, mines are notoriously slow at adopting new technology and so the rate of return on an investment in mining innovation is slow, unless the return is fast and comprehensive. 
We believe the best insight into what we will do next in mining can be found within the recent history of the industry. We believe that the coming changes will not be a comfortable transition from one power source to another, or the slow integration of artificial intelligence into existing equipment systems. We believe that a radical transformation of the technology and the people involved in the mining industry will happen and that it will be complete in little more than five years. We believe this because this is what happened the last time, and because this is what has to happen in a slow-transition market. The best way to prepare for a tsunami is to study what happened during the last tsunami and change accordingly. This does not mean just looking at the changes that occurred, but examining the underlying processes that brought about those changes and use these to design the system that will survive and thrive.

\section{Theory of Constraints}

We believe the Theory of Constraints (TOC) is a valuable methodology for helping to decide what processes are best suited to continuous equipment systems, and which are best executed as a series of discontinuous, or batch processes.

It is important to make a clear distinction between continuous equipment and continuous system. There are single equipment units that operate continuously to accomplish a set of tasks, but it is also possible to develop a continuous system that comprises several individual equipment units operating in unison to accomplish a set of tasks continuously. Both have value, but the value depends on how well-suited they are to the system conditions in any given situation.

The characteristics of batch (discontinuous) and continuous systems are different, but the selection of one of these for a particular activity is not as simple as it may appear. It may seem obvious that continuous equipment units will lead directly to continuous operation, but in all cases, equipment units must be maintained or refuelled. For a single equipment unit, this may necessitate an interruption to the production process, whereas a continuous system with multiple equipment units can allow each unit to be maintained or refuelled at times when they are not actively operating in the continuous process. The result may be that the multi-unit system can offer a slightly more continuous production process than a single continuous equipment unit can achieve.

The TOC takes a scientific approach to improvement and assumes that every complex system consists of multiple linked activities, one of which acts upon the system as a constraint on the whole system; the weakest link or bottleneck. The approach uses what are called five focusing steps to identify and eliminate constraints, and then applies various processes to analyse and resolve problems, and concludes with throughput accounting for measuring performance. The TOC approach always focuses on the current constraint as the top priority and in situations where there is an urgent need for rapid improvement, the methodology helps focus attention on the highest-priority issues.

A successful application of the TOC will increase profitability, quickly achieve results by focusing on one critical issue at a time, improve the system capacity by optimising constraints and increasing the amount of production, reduce lead times by creating a smoother and faster rate of production, and finally, reduce the inventory of supplies into the production process by reducing bottlenecks.

\subsection{The reality of constraints}

Unfortunately, engineers do not always want to deal with the current constraint. They often want to deal with the most interesting or exciting part of the process, or the one that has the highest profile at the time. Figure 1 (taken from Morrison et al. 2015) shows that some open-stoping operations in Canada limit their production drilling rate to match the constraint of the hydraulic backfill system. If a tailings paste backfill system that can fill stopes in a much shorter time, it would be possible to reduce the total stope cycle time by about $50 \%$. This would allow the operation to either increase production with the same resources or maintain the same production rate with fewer resources. 


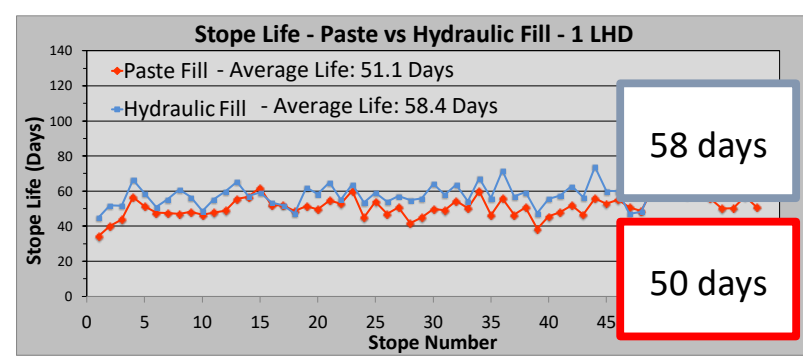

Scenario 1 - Base Case

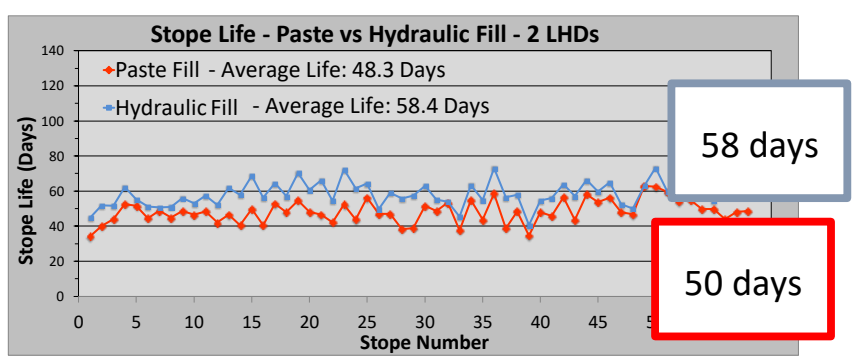

Scenario 2

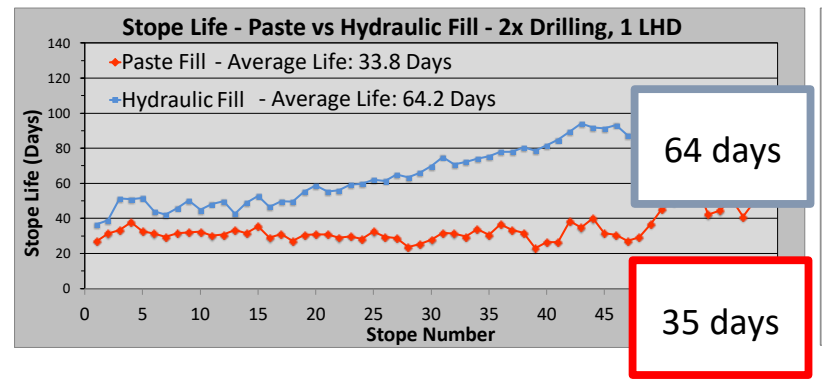

Scenario 3

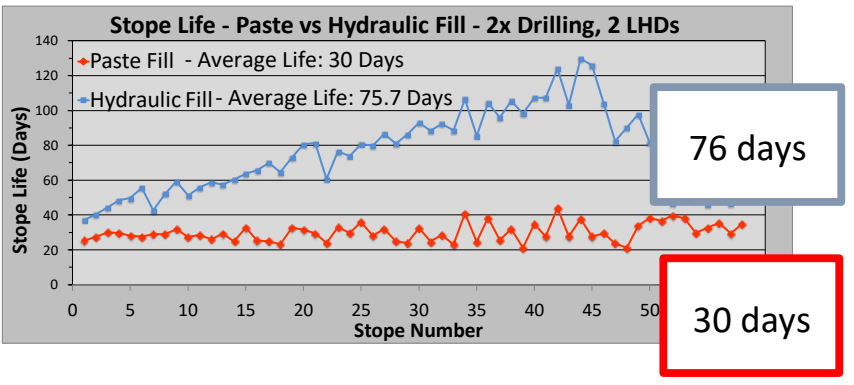

Scenario 4

Figure 1 Stope cycle times using hydraulic (blue) and tailings paste (red) backfill, showing increased production potential from tailings paste backfill

The results in Figure 1 clearly show the reduction in stope cycle time from 58 days for the hydraulic system, to about 50 days for the paste system, and show that doubling the number of load-haul-dump units (LHDs) (Scenario 2) makes very little difference. Doubling the amount of drilling reduces (Scenario 3 ) the cycle time for the paste fill system to 35 days and doubling both drilling and LHDs (Scenario 4) reduces the paste fill system cycle time to 30 days so that introducing paste fill makes it possible to increase the production rate by $40-50 \%$. In contrast, for a hydraulic fill system, the same changes increase the stope cycle time to well over 80 days because of the increase in the number and duration of delays related to preparing stopes for backfilling.

In mines that use backfill as an integral part of the production process, it is not possible to increase the rate of production unless the backfill system already has excess capacity. The introduction of any new production system that increases the ore production rate will be ineffectual if the backfill rate cannot sustain the new production rate - the number and volume of unfilled excavations means the mine will simply run out of sources of production. As unrewarding or uninteresting as it may be, it is essential to create excess capacity in backfill delivery before expending resources to increase the production rate. The same is true for every constraint in the system, and progress can best be made when each constraint is addressed in turn, rather than simply focusing on whatever new technology has just been developed. No innovation can be successful in isolation; every innovation has to be integrated into a production system and there are no simple one-component solutions.

\section{Constraints on mine production systems}

It can be helpful to consider three types of constraints within the mine production system; process constraints, activity constraints and natural constraints. Their distinctions are not rigorously defined; they simply help in focusing attention on different system aspects of mine production.

\subsection{System constraints}

Some processes are, by their nature, batch processes. Any mining method that requires backfilling is a batch process; at some point during the mining process ore production has to be interrupted to accommodate the backfilling cycle. If production equipment units can be redeployed elsewhere during the backfilling cycle, the efficiency of the capital equipment is maintained. 
It is possible to mitigate this process constraint by extracting multiple panels in such a way as to allow one panel to be filled while another is in production, but this requires the continuous equipment to be sufficiently flexible to restart production without interruption. In the case of an inherently discontinuous process, it is relatively easy for discrete equipment units to be redeployed in another production panel during the backfill cycle of the first panel, to provide a continuous production system.

Since the backfill cycle is so completely different from the rest of the mine production process, using completely different equipment, we can easily focus attention exclusively on the ore production process as in the case of mining methods that do not use backfill, such as sublevel caving and block caving. In these cases, we have only two process activities to consider - developing the accesses to the orebody and then generating and transporting the ore.

\subsection{Activity constraints}

Activity constraints are those that are in the nature of the activity itself. Some activities in the mining process are very complicated and highly dependent on manual intervention, and since labour cost is the single largest cost centre, reducing direct human intervention is a common objective. Several activities are already being automated - truck haulage, LHD haulage, and more recently, production drilling, but some activities are less amenable to automation and it may be beneficial to eliminate these activities and replace them with other, more easily automated activities.

One candidate for replacement is access development by drill-and-blast methods - activities that are considered inherently slow and labour intensive. In fact, most of the steps involved in drill-and-blast access development can be completely automated and the activity is not inherently slow - it is certainly possible for innovation to improve the rate of development to around $10 \mathrm{~m} /$ day. Figure 2 (taken from Morrison 2017) shows a canopy system that can achieve this target by enabling concurrent drilling, charging and ground support installation activities in a single heading, when used in combination with a continuous rock removal system. However, continuous rock excavation is now being considered as a viable alternative to the drill-blast methods in underground mines.

Three-canopy system for rapid advance

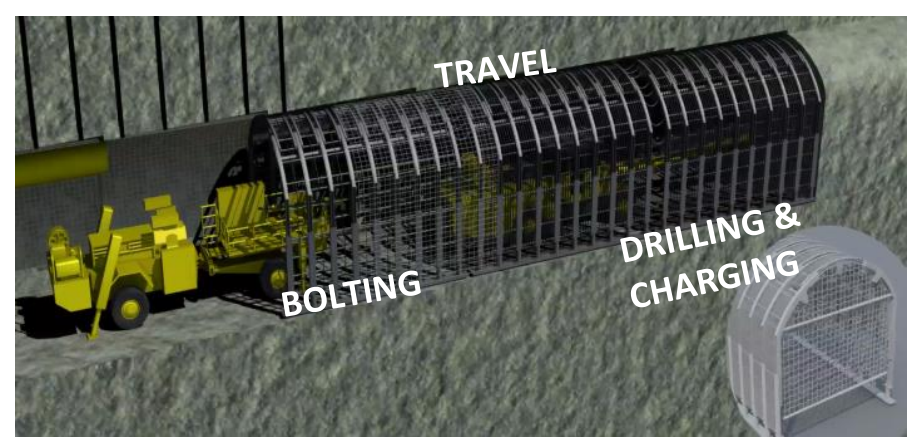

\section{Face shield}

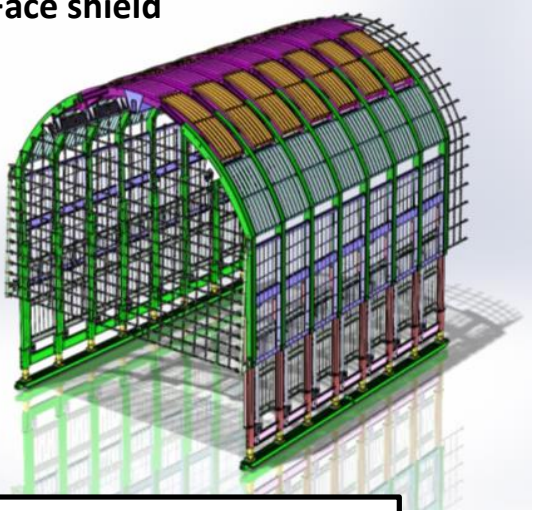

Primary objective: reduce drift cycle: $<\mathbf{1 0 . 5}$ hours $=\mathbf{2}$ cycles per day

Phase 1a - Canopy system; physical barrier to rock-related hazards.

Phase $1 \mathrm{~b}$ - Allow concurrent activities; reduce face cycle $\sim 8 \mathrm{hrs}$.

Phase 2 - Rapid transport of rock; reduce muck cycle $\sim 2$ hrs.

Figure 2 A three-canopy system to enable concurrent activities in a single-heading drift development. The front canopy has a face shield to protect against bursting from the face and charging is done by an automated central boom on the drill carriage

Continuous mechanical excavation techniques have been very successful in many soft rock (sedimentary or meta-sedimentary) settings, especially for long, straight tunnels for road or rail transportation or water delivery industrial settings. The application of these kinds of equipment to hard rock mining situations has 
not yet been successful, but recent developments in rock cutting technology have almost certainly addressed the issue of being able to reliably excavate a variety of igneous and metamorphic rock types. In sedimentary-type deposits such as salt or coal, the mass of the cutting machine is sufficient to ensure the cutting mechanisms actively deploy at the face and do not rebound off the cutting surface without removing material. For much harder rock, it is necessary for the equipment to brace itself to the surface of the excavation to be able to generate enough thrust to impact the face and advance the excavation. The most recent equipment development has overcome these limitations, and only the natural constraints are possible barriers for the application of these new rock cutting systems.

Another important activity is generating broken ore, accomplished either by blasting or by the natural processes within the caving zone in block caving operations. In both cases, however, the management of production activities influence the nature of the broken ore, and so influence the cost and speed of transportation. Ultimately, the primary objective of the mining operations is to increase the ore transfer rate and to do so at the lowest possible cost.

There is always a trade-off in designing production blasting systems between the direct cost of drilling and blasting and the total cost of transporting the ore. Reducing the direct cost of blasting results in poor fragmentation and increases the transportation cost. It is possible to design more-costly drill-blast patterns that will optimise the distribution of explosive energy in the orebody and to generate a uniformly fragmented ore product that will enable much smaller transportation costs. It is badly optimised blasting practices in pursuit of lower direct costs that is responsible for a fragmentation profile that can make the LHD the preferred equipment for ore transfer because of its flexibility and manoeuvrability. Continuous loading equipment offers a higher ore transfer rate at much lower cost (Siemens et al. 2014), and although it is limited by its capacity to manage large material, this can be mitigated with a rockbreaker arm.

In block caving operations, there is a broader range of fragmentation in drawpoints, with more large material than is common in ore that has been blasted. In mature drawpoints with more finely fragmented material, it is possible to use continuous loading systems, but in drawpoints opened soon after the drawbell is completed, the fragmentation profile is such that extraction will be limited to LHDs. In this case, the nature of the activity constraint is changing throughout the duration of the process and it is reasonable to expect the optimal loading technology might change also.

The obvious means to assess the constraints in a production setting are with performance-related measures, such as rate of rock cutting, rate of advance, rate of drilling, rate of ground support installation, rate of production, rate of backfilling, and rate of ore transfer. The TOC will try to harmonise these measures to make them operate in unison, so as to minimise any loss of production caused by a mismatch of the rate of outputs in sequential activities.

Just as important, however, are the constraints imposed by the natural conditions in the operating setting factors such as variability and complexity.

\subsection{Natural constraints}

Natural conditions are factors such as heat, humidity, rock stress, and the complexity of the disposition of the orebody. Many narrow vein deposits have necessarily complicated access configurations that follow the ore, while large porphyry-type deposits are much more uniform and can tolerate relatively simple, regular excavation layouts. Mines shallower than $1,000 \mathrm{~m}$ depth have few heat and humidity problems, and kinetic ground-falls can be reliably controlled. Deeper mines have more-severe heat and humidity problems that are expensive to mitigate conventionally, and they experience seismicity-induced rockburst damage that is not predictable in time or space, and that means excavation reliability (a combination of safety and stability) is highly variable.

For these natural constraints, the only option is to mitigate the constraint. In a complex and variable setting, flexibility and manoeuvrability are more-valuable attributes than energy- and cost-efficiency. 


\section{$4 \quad$ The last process transformation}

The transformation of the underground mining industry that occurred around 1980-1985, changed the technology platform from manpower-intensive mining methods and pneumatic equipment to capital-intensive mining methods using larger, diesel-powered electric-hydraulic equipment. This dramatically increased the productivity of many mines, delivering more product with less labour and the higher cost of individual equipment units was easily recovered by their ability to deliver more ore faster. Overall, the dramatic increase in productivity achieved by this transformation was a very significant process improvement, but its very success served to camouflage some of the system changes that had been made during the transition.

The introduction of longhole drilling increased the burden on spacing of blastholes so that the relatively well-graded product became a more poorly graded fragmentation profile, with a higher percentage of the whole as larger product sizes, and more dust. The most obvious problem was the creation of oversize material that required secondary blasting. The more subtle change was the increase in the percentage of undersize (dust) created by the pulverising of material in the annulus around the blastholes. In the case of base metal sulphide mines, the softer, higher-grade material preferentially reports as undersize and the lower-grade material tends to present as larger material. Larger material contributes to increasing cost either by secondary blasting or simply causing wear and tear on equipment, and the higher-value product is lost in the floor. Some precious metal mines ensure the recovery of high-value fines by using vacuum units but these are uncommon in most base metal mines.

The fundamental process change that occurred was from a holistic production process to a prescriptive production process. In selective mining methods, one crew is engaged in every component of the production process, removing broken ore, installing ground support, drilling the new round, and charging holes with explosives ready for blasting. This is a holistic process (Morrison 1991) in which there is an internal feedback loop; if the crew executes a blast badly, it will create more work in the next part of the cycle - either for removing badly broken ore, or excessive rock damage needing more ground support. In any event, it is more work for the same crew and they typically hone down their work practices to make sure that the production process is as smooth and efficient as possible. This minimises their effort and maximises their benefit within the incentivised production process.

In a bulk mining production system, the same four activities are executed in sequence, but by four distinct crews that each only execute one of these activities. This is a prescriptive process where distinct workers or groups of workers repeat the same prescribed activity. There is a dedicated development crew to create the stope accesses and egresses, and thereafter, ore production is accomplished by three separate activities. Typically, each activity is incentivised independently with little consideration of the factors that make the other activities in the system easier or more cost-effective to achieve. Without integrating the activity incentives, there is no inherent feedback loop to improve system performance.

These same changes also increased the cost of accessing orebodies as large equipment requires larger access tunnels or drifts. Larger drifts at greater depth and under greater rock stress require more reinforcement to maintain the same level of stability as smaller excavations at the same depth or the same sized drifts at lower-stress, shallower conditions. As mines became deeper, the result was an increase in the cost of access development, removing more waste and installing more support, and speed of accessing new orebodies decreased. As equipment size increased further to gain some performance objective (faster drilling or more tonnes carried), the negative impact of larger drifts at higher ambient stresses has been exacerbated.

When the new production processes were first introduced, the impact of lowering net present value by slowing the access rate to new orebodies was masked by the benefit of the very large increase in production rate in existing orebodies. Above $2,000 \mathrm{~m}$, rock stresses allowed relatively high stopes with a high sublevel interval. However, deeper, higher-stressed orebodies have to be mined with lower stope heights, increasing the capital cost of more-frequent level intervals. The overall effect is to increase the cost of production. 
As many of these orebodies are depleted, and access to new, more-distant and deeper underground orebodies is necessary, the effect of slow development rates exacts a greater toll on the value of a mineral deposit.

The transformation from selective mining technology platform to the bulk mining method technology platform was tremendously successful, but with all of the system changes that occurred, something was gained and something was lost. As the initial benefits of the new technology are eroded, the impact of the benefits that were lost have become more evident. The result is a 'progress trap'.

\section{The progress trap}

In the transformation of the mining process from low to high productivity, from selective to bulk, from holistic to prescriptive, something obvious was gained and something more subtle was lost. The changes were implemented because they created an immediate gain for the system, but the change often concealed a critical change in the process that would only become obvious much later.

This is what Wright (2004) called a progress trap; the early gains that created a more-profitable solution to a problem are gradually lost and if the real cause of the decline is not addressed, it will lead to a system collapse. The best examples are Mesopotamia, Mesoamerica and Easter Island, where the development of a more-productive agricultural system led to a population boom that eventually exceeded the maximum capacity of the new system and led to a collapse of the society. Too often, rather than recognise the error, system planners have usually doubled down on the benefits of scale and power and have simply shortened the economic life of the operation. Local religions insisted that the gains were the result of the beneficence of a higher power and that the declines were due to the displeasure of this same power. The initial solutions to the decline were initially more prayers and genuflections, but later they were greater labour intensity and higher taxes, followed by giant stone heads, higher cathedrals and pyramids and more human sacrifices either explicitly on an altar or implicitly within an unsustainably brutal production system - and which simply accelerated the final collapse. Recent history of the mining industry is replete with analogies to each of these false prophets.

One possible escape route is to recognise that the scale and process issues that mines are struggling with have camouflaged the distinction between the efficiency and effectiveness of the systems themselves. The pneumatic equipment that quickly became obsolete after 1980 was grossly underpowered compared to the highly energy-efficient equipment that replaced it. After all, it was the scale and power of the equipment that won the competition and men are particularly susceptible to these attractions. But the pneumatic-powered, manual equipment was also more effective in its process. It was only one step beyond the purely manual equipment that preceded it and the people that operated this equipment relied on an automatic feedback loop to reduce the wear and tear on the most susceptible component in the system themselves. In a production system dominated by piecework incentives, the equipment operators took great care to make sure their production process was as low-wear and high-value as possible. With the introduction of more-powerful equipment, the drive to optimise the nature of the activity was lost and the focus on increasing scale and power began.

\subsection{Escape from a progress trap}

Escape from a progress trap is not easy. In our short history on earth, most societies that found themselves in a progress trap were unable to find a way out of their own trap. Those societies that were trapped on an island or in one geographic location simply collapsed. European society effectively escaped its progress trap by relocating to the Americas, where they proceeded to devastate the local populations, some of whom have already experienced their own progress traps, and then began to reinstitute the same kind of societal structures they had left behind. Those remaining in Europe tried two major social engineering experiments, laissez faire capitalism and communism, that led to a century of social and economic devastation and mass slaughter. As we begin to see the dangers of another effect of the industrial revolution, global warming, we are beginning to realise that we have to learn how to solve the problem of the progress trap. Dreams of escape to another planet are just that - dreams. The problem has to be solved here, by us. Or not. 
The same is true in mining. There is no escape to newer, fresher pastures with easy-to-access high-grade ores. The one unexploited continent, Antarctica, is no paradise, and even if we were to start mining there, it would not meet the needs of our immediate future. We have to begin solving the problem now.

Neither is there a simple technological solution. A progress trap is a subtle and complex configuration and simplistic, magic-bullet solutions are simply not sufficient. One approach that will certainly fail, as it has in the past, is to compound the problem by even greater application of scale, speed and force. We will have to match the subtlety and complexity of our progress trap with the ingenuity, creativity and imagination that has brought us the gains that we have enjoyed, and upon which our society now depends.

In the last transformation of underground mining technology, we gained equipment efficiency many times over, but we lost on process effectiveness. The next transformation must retain the gains in efficiency, make them less costly through optimisation and then design a production process that is much more effective.

\section{Conclusion}

There is no absolutely correct answer to the selection of continuous or discontinuous equipment systems in mines; they are different systems for different tasks. Some processes have to be executed under conditions that are highly variable and high risk, and others have to operate in relatively stable, unchanging, lower-risk conditions. Risk does not mean safety; it is possible today to remove people from almost every activity that comprises the ore production process. Risk remains whether people are involved in the process or not. The objective of the system designer is to employ the techniques and equipment that are best able to execute the necessary activity and be able to survive or recover from the damaging, unpredictable high-risk events that might occur, and to accomplish this at the lowest possible cost.

We have to recognise that we are in a progress trap that we have to understand before we can escape. The mining industry is one of the two founding pillars of civilisation, the other being agriculture, and we can learn more from our own past than we can from other sectors of the modern economy. However, we cannot afford to continue to reinforce the current trend, and we have little time for guesses or hopes-for-the-best. A systems approach is the best way to figure this out.

From a systems point of view, the optimal solution is achieved by matching the constraints on the mining process with equipment that has the characteristics best suited to overcome those constraints, to arrive at the optimum balance of effectiveness and efficiency. At the high-risk end of the spectrum, in highly complex configurations with unpredictably variable events, the best attributes are mobility, manoeuvrability and flexibility, for maximum effectiveness (even at the expense of cost and human intervention). At the relatively stable, low-risk end of the spectrum, the best attributes for equipment are simplicity, robustness, low maintenance, low energy, and continuous autonomy, for maximum efficiency (with minimal operating cost and human intervention). The success of very deep, challenging mines of the future will depend on making these kinds of choices and having a supply chain that meets these needs. Without them, these mines have no future.

\section{References}

Deloitte Touche Tohmatsu Limited, Tracking the Trends 2017, viewed 23 July 2018, https://www2.deloitte.com/content/ dam/Deloitte/au/Documents/energy-resources/deloitte-au-er-tracking-the-trends-2017-010217.pdf

Morrison, DM 1991, 'Management of technology in hardrock mines', Proceedings of the CIM 93rd Annual General Meeting, Canadian Institute of Mining, Metallurgy and Petroleum, Westmount.

Morrison, DM 2017, 'Transforming the metal mining industry', Proceedings of Mines and Technology 2017, Mines and Money, London.

Morrison, DM, Webb, R, Akerman, A \& Parsons, H 2015, 'Mine design impact on operating and capital costs', in Y Potvin (ed.), Proceedings of the International Seminar on Design Methods in Underground Mining, Australian Centre for Geomechanics, Perth, pp. 433-442.

Siemens, J, Jansen van Rensburg, G \& Vender Merve, F 2014, Continuous Loading - a safe, efficient and productive alternative for the loading of muck at the development face', Proceedings of the 6th International Platinum Conference, The Southern African Institute of Mining and Metallurgy, Johannesburg, pp. 281-290.

Wright, R 2004, A Short History of Progress, House of Anansi Press, Toronto, pp. 29-53. 